УДК 621.396

\section{КОНЦЕПЦІї ПОБУДОВИ СУЧАСНИХ МЕРЕЖ}

\section{ГЛОБА Л.С., СКУЛИШ М.А., ТИМЧЕНКО І.О.}

Описуються технології SDN, SDR, NFV, Big Data, IoT та їх реалізація за допомогою хмарних сервісів, що є невід'ємною частиною мереж 5G. Детально розглядається концепція SDN. Визначаються недоліки хмарних мереж радіодоступу та можливі шляхи їх подолання. Пропонується сегментація мережі C-RAN 3 резервуванням елемента управління та поділ керуючого віртуального контролера на дві площини.

Ключові слова: гетерогенна мережа, макросоти, мікросоты, енергоефективність гетерогенної мережі.

Key words: heterogeneous network, macrocells, microcells, energy efficiency of a heterogeneous network.

\section{Вступ}

На сьогоднішній день можна виділити такі основні технології, що формують сучасні мережі: концепція програмно-визначених мереж - Software-Defined Networks (SDN), технологія програмованого радіо - Software-Defined Radio (SDR), віртуалізація мережевих функцій - Network Functions Virtualization (NFV), великі дані Big Data, Інтернет речей - the Internet of Things (IоT) та так звані хмарні сервіси.

Системи нового покоління мобільного зв'язку 5G будуть базуватися на концепції, орієнтованій на користувача замість орієнтації на оператора, як в $3 \mathrm{G}$ або на сервіс-центри, як в 4G. Це означає, що декілька вхідних потоків з різних технологій будуть об'єднані на мобільних етапах [1]. I тут дуже вагому роль грають програмно-керовані мережі.

Технологія SDN забезпечує більш ефективний розподіл радіоресурсів завдяки централізації, безперебійній мобільності через різноманітні технології за допомогою спільної контрольної площини. Також мобільні мережі нового стандарту не обходяться без великих центрів обробки даних. Концепція SDN дозволяє скоротити витрати на супровід мережі за рахунок тієї ж централізації управління на програмному контролері, підвищуючи частку використовуваних ресурсів мережі завдяки динамічному управлінню [2].

Віртуалізація - це перетворення функцій на програмне забезпечення. SDN та NFV дозволяють спростити конфігурацію мереж, масштабувати мережі і сервіси за запитом користувача, автоматизувати управління мережею, збільшити потужність фізичної інфраструктури шляхом накладення віртуальної, знизити САPEX і OPEX, а в перспективі - швидко реконфігурувати бізнес під поточні завдання [3].

Big Data мають дуже великі об'єми, а їх структуpa $\epsilon$ досить складною, через це їх неможливо легко обробляти (зафіксувати, аналізувати, візуалізувати, зберігати або ділитися) за допомогою традиційних систем керування даними. Останнім часом експерти галузі почали складати схеми перспектив використання великих технологій передачі даних з SDN. У сукупності з правильними додатками SDN може надати користувачам прості, масштабовані, повноцінні мережеві рамки, які ефективно містять і обробляють великі дані [4].

Завдяки IоT будь-який пристрій, що має доступ до мережі Інтернет, здатен віддалено збирати та обмінюватися інформацією в режимі реального часу, а також надавати інтелектуальні послуги за наявності адекватної мережевої інфраструктури. Значну корисність для застосування IоT має технологія програмно-визначених мереж [5]. SDN забезпечує гнучкість та програмність у мережі IoT, не заважаючи основній архітектурі існуючих реалізацій.

В епоху нового покоління зв'язку 5G бездротова мережа повинна задовольняти потреби користувачів у надвисоких швидкостях передачі даних. Має сенс інтеграція технологій NFV 3 SDR та $\mathrm{SDN}$, яка $є$ необхідною для інтелектуальних гетерогенних мереж (HetNets) [6]. Великі міжнародні організації по стандартизації електрозв'язку, включаючи WINNF, ONF, ETSI, ITU$\mathrm{T}$, IEEE, також ведуть активну діяльність по створенню технічної основи та публікації докладних специфікацій для цих трьох технологій, що свідчить про їх значущість та перспективність.

У майбутньому кожна з усіх вище згаданих технологій і концепцій буде невід'ємним компонентом будь-якої мережі (рис. 1).

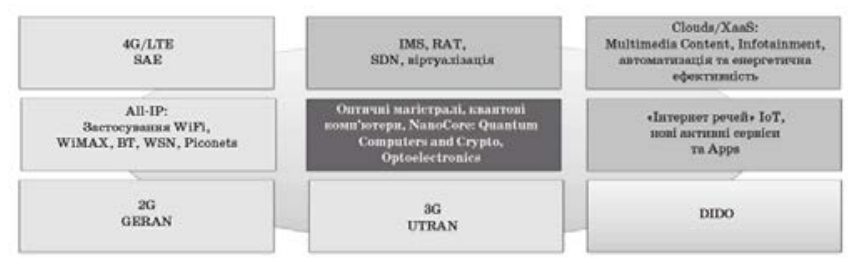

Рис. 1. Узагальнена архітектура мережі нового покоління

\section{1. Программно-керовані мережі}

Мережа, яка визначається програмним забезпеченням, так звана Software-defined network (SDN), позиціонується як нова інтелектуальна архітектура для існуючих мереж. Вона зменшує 
апаратні обмеження, за рахунок розподілу транспортного рівня та рівня управління, на якому керування відбувається завдяки логічному програмному компоненту - контролеру (рис. 2).

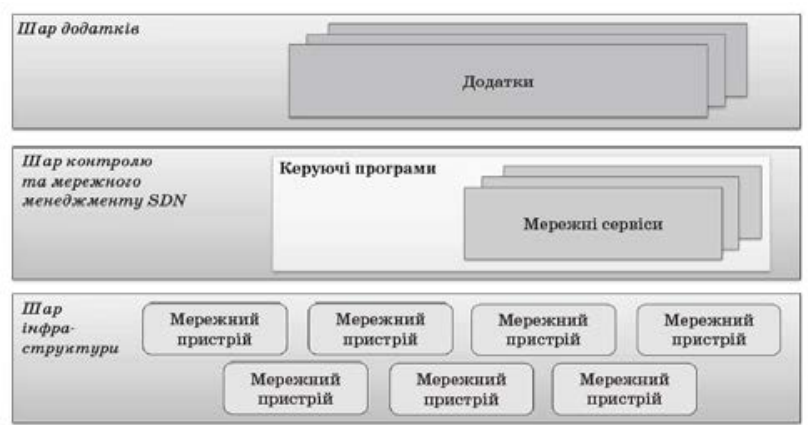

Рис. 2. Архітектура SDN

Контролер виконує моніторинг мережевих пакетів, визначає політику або вирішує помилки згідно 3 результатами моніторингу. Взаємодію між площиною керування та мережевими пристроями забезпечує стандарт OpenFlow.

Ця схема дозволяє розподіляти ресурси за запитом, надавати послуги самообслуговування, забезпечувати повністю віртуалізовані мережі та захищати хмарні сервіси. Таким чином, статична мережа перетворюється на справді гнучку платформу для надання послуг, яка може швидко реагувати на зміни в мережі, такі як: динамічний зріст вимог та потреб кінцевих користувачів та ринку. Крім того, самим пристроям більше не потрібно розуміти і обробляти тисячі протокольних стандартів, вони лише повинні бути спроможними розуміти вказівки з контролерів SDN [7].

Кінцевою метою SDN є створення мережі, що реалізована та функціонує повністю автоматично. Адміністратори можуть більш легко керувати мережею через плату контролера, диктуючи необхідну політику маршрутизаторам і комутаторам, тоді як вони повністю контролюють роботу мережі. Ідеї програмованої мережевої інфраструктури у поєднанні з іншими провідними технологіями виводять на новий рівень побудову сучасних мереж.

Програмно-керовані мережі забезпечують побудову інфраструктурних «хмарних сервісів». Ефективне автоматичне управління необхідне, коли за запитом споживачів послуг виникає потреба автоматично і якнайшвидше створювати віртуальні вузли і виділяти віртуальні мережні ресурси для них.

В контексті хмарних рішень виділяють три основні моделі надання послуг: Infrastructure-as-aService (IaaS), Platform-as-a-Service (PaaS),
Software-as-a-Service (SaaS). На рис. 3 зображено розподіл рівнів відповідальності між користувачем та провайдером послуг для кожної з вказаних вище моделей. Надання таких послуг є вигідним для провайдера цих послуг, адже використовується принцип Revenue Sharing: $є$ клієнт - $€$ прибуток, немає клієнта - немає витрат.

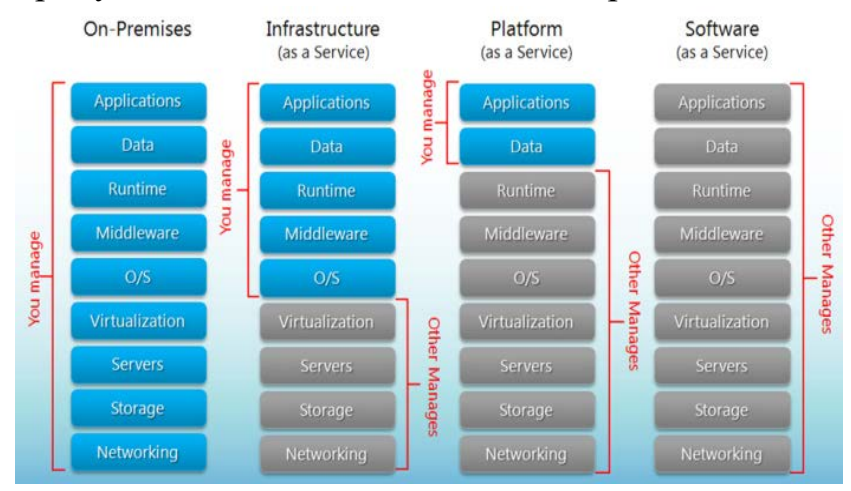

Рис. 3. Моделі обслуговування SDN

До головних переваг SDN можна віднести:

1. Централізоване управління мультивендорним середовищем.

2. Спрощення обслуговування i модернізації мереж.

3. Скорочення часу на оновлення програмних кодів комутаторів/маршрутизаторів i впровадження нових сервісів.

Мережі, керовані програмним забезпеченням, представляють неабияку цінність для бізнесу, а саме: спрощують конфігурацію та експлуатацію мережі, користувач отримує вендоронезалежний контроль над всією мережею з єдиного місця, скорочуються терміни впровадження нових додатків і сервісів.

Перший комерційний стартап-проект із побудови програмно-конфігурованої мережі реалізувала компанія Nicira [8]. Ï̈ клієнтами стали NTT docomo, AT\&T, EBay, Rackspace. Пізніше американська компанія VMware купила Nicira за рекордні для галузі \$ 1,26 млрд.

В 2011 році було створено Open Networking Foundation - некомерційну організацію, основним завданням якої була популяризація нового підходу до управління комп'ютерними мережами - SDN. Ініціаторами виступили 6 компаній - власники найбільших у світі мереж - Deutsche Telekom, Facebook, Google, Microsoft, Verizon, i Yahoo. Дуже швидко до консорціуму приєдналися всі основні виробники мережевих рішень, включаючи Cisco, Brocade, NEC, HP [9].

Перша велика мережа SDN була реалізована в 2012 році компанією Google на базі комутаторів власної розробки. Керування перенаправленнями 
потоків трафіка між ЦОДами здійснювалось в режимі реального часу 3 урахуванням економічної вигоди в конкретний поточний момент. Технологію SDN також використовують фірми Pertino, Telecom Italia i ряд інших компаній.

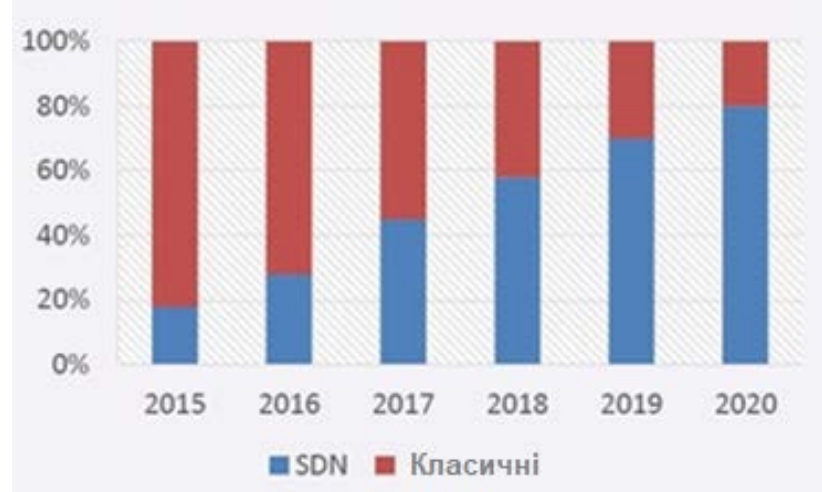

Рис. 4. Динаміка росту співвідношення SDN/класичні мережі

На зорі зародження самої технології ій пророчили масове впровадження до 2016 року, та хоча цього не сталось, прогнози щодо розвитку залишилися такими ж перспективними, але тепер кажуть про 2020-2022 роки. Обсяг ринку зазначених мереж у 2012 році становив близько \$200 млн, тоді ж говорили й про його зростання до \$2,1 млрд не пізніше як до 2017 року, а вже у 2015 році мали місце інші прогнози: за даними Infonetics Research, у 2018 році обсяг SDN має становити \$11 млрд, а в 2019 позначка сягне \$13 млрд в порівнянні з $\$ 781$ млн в 2014 році. На рис. 4 відображено частку SDN серед класичних мереж.

Деякі фахівці також притримувалися думки, що протокол OpenFlow відживе своє, проте протокол не помер і поки є найбільш готовим до використання в реальних мережах і $\epsilon$ навіть список вендорів, у яких можна купити обладнання 3 підтримкою OpenFlow версії 1.3.4. Але плюсом до нього з'явилися ще кілька: Protocol Oblivious Forwarding (РОF) від Huawei та P4 (Programming Protocol-independent Packet Processors) від Open Networking Research Center (Стенфорд) [10].

По суті OpenFlow - це поки єдина реалізація $\mathrm{SDN}$, яка обіцяє чесну незалежність від виробника. Всі великі вендори пропонують свої рішення SDN і в тій чи іншій мірі розширили можливість керування пристроями в мережі, але рішення різних вендорів між собою поки що практично не сумісні. Всі великі оператори зв'язку придивляються до технології, підбирають команди, які зможуть працювати 3 новими технологіями, пла- нують перебудову бізнес-процесів. Можливо в найближчі 2-3 роки можна буде вже говорити про початок стадії впровадження.

\section{2. Технологія хмарної мережі радіодоступу}

За принципом SDN розвиваються також мережі радіодоступу. Концепція хмарної радіомережі (C-RAN) передбачає відокремлення радіопідсистеми (Remote Radio Heads, RRHs) і антени від модулів управління базової станції (Baseband Units, BBUs), які розташовуються в так званому base station hotel (BSH) і з'єднуються через оптоволоконний кабель 3 блоками RRHs [11]. Таким чином, оператори можуть будувати хмарні мережі радіодоступу за принципом NFV, розміщуючи в хмарі основний функціонал базової станції, що відповідає за цифрову обробку сигналу, синхронізацію, управління, збір статистики. Загальна схема віртуалізованої мережі радіодоступу представлена на рис. 5 .

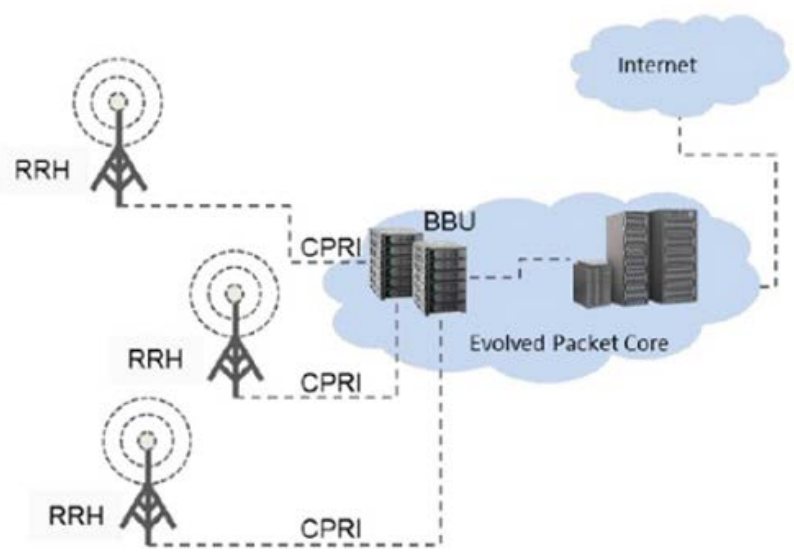

Рис. 5. Архітектура Cloud RAN

Проте існує ряд недоліків таких систем. Перший важливий недолік пов'язаний $з$ централізацією, тобто вразливість центральної базової станції BBU до хакерських атак та фізичних несправностей. Це означає, що для забезпечення безперебійної роботи є необхідним резервування центрального блоку керування додатковим обладнанням, при цьому «резервний комплект» буде простоювати весь час, поки не відбудеться збій.

Для вирішення цієї проблеми пропонується поділити мережу на кілька сегментів, кожний з яких буде мати свій елемент управління, a RRHs будуть пов'язані з двома BSH, які у разі аварійного стану основної віртуальної базової станції здатні заміщати одна одну. Така схема також дає змогу уникнути роботи резервного обладнання «вхолосту».

Наступним недоліком є помилка в програмуванні центрального елемента управління, адже це може призвести до серйозних проблем на всій ме- 
режі. Некоректно розподілені мережеві ресурси впливають на продуктивність роботи BBU, що у свою чергу впливає на правильність обробки сигналів тощо. Зарадити в такій ситуації може лише перевірене програмне забезпечення та його тестування перед застосуванням на реальній робочій мережі.

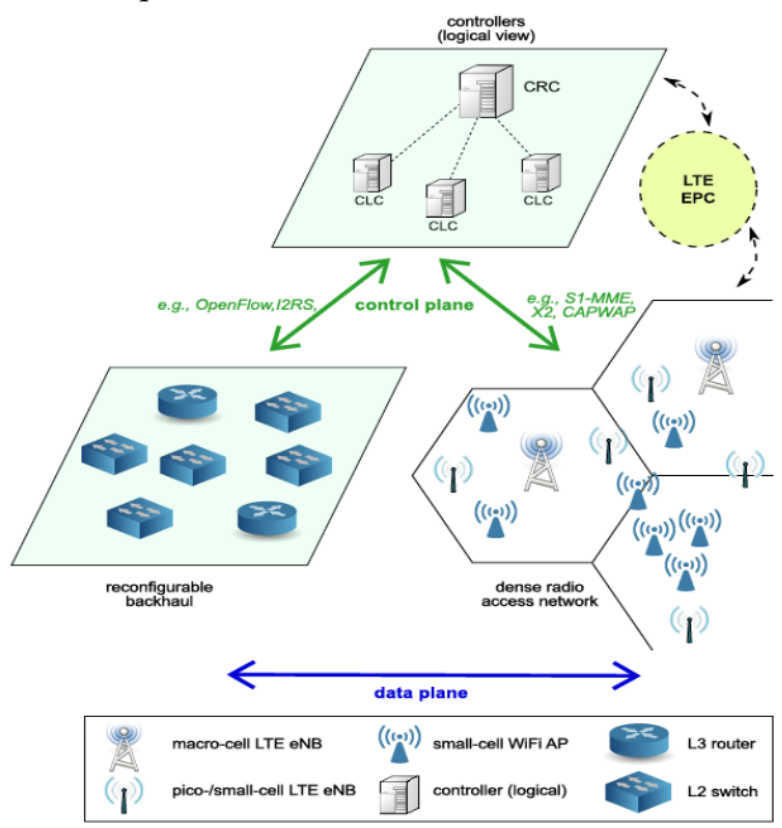

Рис.6. Архітектура мережевого управління

Пропонується інший варіант подолання цього недоліку - архітектура мережі міститиме дві контрольні площини, подібно до мережі LTE, що застосовує архітектуру CROWD (рис. 6) [12]. Контролер буде мати головний елемент управління (ГЕУ) та декілька локальних елементів управління (ЛЕУ), що резервуватимуть один одного, причому обидва $\epsilon$ логічними елементами, розвернутими у хмарі, проте на різних фізичних серверах. Головною задачею ЛЕУ $\epsilon$ короткострокова локальна оптимізація, а ГЕУ виконує глобальну оптимізацію на основі довгострокового моніторингу та статистики і координує роботу підпорядкованих ЛЕУ.

Така архітектура на основі Cloud RAN дозволяє вільно запускати безліч додатків управління, які можуть точно налаштувати роботу мережі з різними критеріями оптимізації, наприклад, пропускною спроможністю, енергоефективністю.

Існують також нетехнологічні проблеми, такі як висококоштовна кардинальна перебудова існуючих мереж, перекваліфікація кадрів, обмежена кількість мережевого обладнання, що націлене на конкретне використання OpenFlow та необхідного ПЗ. 3 часом ці недоліки можуть зійти нані- вець, проте зараз масштабне розгортання подібної мережі доступне лише великим компаніям. Особливістю SDN є відділення функцій передачі трафіка від функцій управління, включаючи контроль як самого трафіка, так і пристроїв, що здійснюють його передачу. Згідно $з$ цією концепцією, вся логіка управління виноситься в контролери, які здатні відслідковувати роботу всієї мережі. Роз'єднання мережевого контролю і ліній передачі даних забезпечує спрощене мережеве управління та полегшує введення нових послуг або змін у мережу.

\section{Висновки}

У сукупності з іншими концепціями, такими як NFV, SDR, Big Data, IoT, Cloud computing, програмно-керовані мережі є основою для побудови сучасних мереж, здатних задовольнити потреби звичайних і бізнес-користувачів. Прогнози щодо масового впровадження SDN залишаються оптимістичним, тільки пролонгованими у часі.

Проаналізовано тенденції розвитку систем керування мережами зв'язку. Досліджено недоліки Cloud RAN-мереж: зупинка роботи мережі при виході з ладу центрального елемента управління, можливість помилки у ПЗ, затримка при отриманні інформації контролером про вихід з ладу або завантаженість каналу. Визначені методи боротьби 3 наведеними вище недоліками, запропоновані поділ мережі на сегменти і резервування BSH, а також застосування двох площин управління: головну і локальну.

\section{Література:}

1. Zolanvari $M$. SDN for 5G / Maede Zolanvari // Rotation October 2015.

https://www.cse.wustl.edu/ jain/cse570-15/ftp/sdnfor5g.pdf 2. Лунтовський А.О. Застосування технологій SDN для програмної реалізації провайдерського ядра систем мобільного зв'язку 5G майбутнього покоління / А. О. Лунтовський, А. I. Семенко // Зв'язок, 2014. № 3. С. 13-19.

3. Sarigiannidis P. Hybrid 5G optical-wireless SDN-based networks, challenges and open issues / Panagiotis Sarigiannidis, Thomas Lagkas, Stamatia Bibi // IET Networks - Volume: 6, Issue: 6, p. 141-148 - DOI: 10.1049/iet-net.2017.0069. 2017.

4. Mohammed A. Alqarni Benefits of SDN for Big data applications / Mohammed A. Alqarni // 14th International Conference on Smart Cities: Improving Quality of Life Using ICT \& IoT (HONET-ICT), IEEE - Electronic ISSN: 1949-4106 DOI: 10.1109/HONET.2017.8102206. 2017.

5. Bera S. Software-Defined Networking for Internet of Things: A Survey / Samaresh Bera, Sudip Misra, Athanasios V. Vasilakos // IEEE Internet of Things Journal, Volume: 4, Issue: 6, Dec. 2017.

6. Sun S. Integrating Network Function Virtualization with SDR and SDN for 4G/5G Networks / Songlin Sun, Michel Kadoch, Liang Gong, Bo Rong // IEEE Network 29(3): p.54-59 DOI10.1109/MNET.2015.7113226. 2015. 
7. Hakiri A. Leveraging SDN for The 5G Networks: Trends, Prospects and Challenges / Akram Hakiri, Pascal Berthou // arXiv:1506.02876. 2015.

8. Mendiola A. A Survey on the Contributions of SoftwareDefined Networking to Traffic Engineering / Alaitz Mendiola, Jasone Astorga, Eduardo Jacob // DOI: 10.1109/COMST.2016.2633579 - IEEE Communications Surveys \& Tutorials -Volume: 19, Issue: 2. P. 918-953. 2017.

9. About ONF Mission / Official website of the Open Networking Foundation. https://www.opennetworking.org/mission/

10. Shengru Li. Protocol Oblivious Forwarding (POF): Software-Defined Networking with Enhanced Programmability / Shengru Li, Daoyun $\mathrm{Hu}$, Wenjian Fang // DOI: 10.1109/MNET.2017.1600030NM - IEEE Network Volume: 31, Issue: 2, March/April 2017. P. 58-66.

11. Скулиш М. А. Метод контролю якості обробки інформаційних потоків у мережі 5G / М. А. Скулиш, А. А. Заставенко // Вісник Національного університету "Львівська політехніка". Радіоелектроніка та телекомунікації, 2016, № 849 , с. $265-273$.

12. Mancuso V. A prototyping methodology for SDN-controlled LTE using SDR / Vincenzo Mancuso, Christian Vitale, Rohit Gupta, Karamvir Rathi, Arianna Morelli - January 2017 https://www.researchgate.net/publication/312661126_A_prototy ping_methodology_for_SDN-controlled_LTE_using_SDR

Transliterated bibliography:

1. Zolanvari M. SDN for 5G / Maede Zolanvari // Rotation. 2015.

https://www.cse.wustl.edu/ jain/cse570-15/ftp/sdnfor5g.pdf

2. Luntovskiy A.O. Zastosuvannya tehnologii SDN dlya programnoi realizatsii provayderskogo yadra system mobilnogo zvyazku 5G maybutnogo pokolinnya / A. O. Luntovskiy, A. I. Semenko // Zvyazok, 2014, № 3, C. 13-19.

3. Sarigiannidis $P$. Hybrid $5 \mathrm{G}$ optical-wireless SDN-based networks, challenges and open issues / Panagiotis Sarigiannidis, Thomas Lagkas, Stamatia Bibi // IET Networks - Volume: 6, Issue: 6, p. 141-148 - DOI: 10.1049/iet-net.2017.0069. 2017.

4. Mohammed A. Alqarni Benefits of SDN for Big data applications / Mohammed A. Alqarni // 14th International Conference on Smart Cities: Improving Quality of Life Using ICT \& IoT (HONET-ICT), IEEE - Electronic ISSN: 1949-4106 DOI: 10.1109/HONET.2017.8102206. 2017.

5. Bera S. Software-Defined Networking for Internet of Things: A Survey / Samaresh Bera, Sudip Misra, Athanasios V. Vasilakos // IEEE Internet of Things Journal, Volume: 4, Issue: 6, Dec. 2017.

6. Sun S. Integrating Network Function Virtualization with SDR and SDN for 4G/5G Networks / Songlin Sun, Michel Kadoch, Liang Gong, Bo Rong // IEEE Network 29(3): p.54-59 DOI10.1109/MNET.2015.7113226. 2015.

7. Hakiri A. Leveraging SDN for The 5G Networks: Trends, Prospects and Challenges / Akram Hakiri, Pascal Berthou // arXiv:1506.02876 . 2015.

8. Mendiola A. A Survey on the Contributions of SoftwareDefined Networking to Traffic Engineering / Alaitz Mendiola, Jasone Astorga, Eduardo Jacob // DOI: 10.1109/COMST.2016.2633579 - IEEE Communications Surveys \& Tutorials -Volume: 19, Issue: 2. P. 918-953 Secondquarter 2017.

9. About ONF Mission / Official website of the Open Networking Foundation. https://www.opennetworking.org/mission/

10. Shengru Li. Protocol Oblivious Forwarding (POF): Software-Defined Networking with Enhanced Programmability / Shengru Li, Daoyun Hu, Wenjian Fang //
DOI: 10.1109/MNET.2017.1600030NM - IEEE Network Volume: 31, Issue: 2, March/April 2017. P. 58-66.

11. Skulish M. A. Metod kontrolyu yakosti obrobky Informatsiynyh potokiv u merezhi 5G / M. A. Skulish, A. A. Zastavenko // Visnyk Natsionalnogo universytetu "Lvivska politehnika". Radioelektronika ta telekomunikatsii, 2016, № 849. C. 265-273.

12. Mancuso $V$. A prototyping methodology for SDN-controlled LTE using SDR / Vincenzo Mancuso, Christian Vitale, Rohit Gupta, Karamvir Rathi, Arianna Morelli - January 2017 https://www.researchgate.net/publication/312661126_A_prototy ping_methodology_for_SDN-controlled_LTE_using_SDR.

Поступила в редколлегию 15.01.2018

Рецензент: д-р техн. наук, проф. Безрук В.М.

Глоба Лариса Сергіївна, д-р техн. наук, проф., кафедри інформаційно-телекомунікаційних мереж Національного технічного університету України «Київський політехнічний інститут імені Ігоря Сікорського». Наукові інтереси: інтелектуальні системи підтримки прийняття рішень, розподілені системи і технології. Адреса: Україна, 01033, Київ, пров. Індустріальний, 2, моб. тел. +38(050)5261512.

Скулиш Марія Анатоліївна, канд. техн. наук, доцент кафедри інформаційно-телекомунікаційних мереж Національного технічного університету України «Київський політехнічний інститут імені Ігоря Сікорського». Наукові інтереси: безпека в телекомунікаційних системах, системи тарифікації в телекомунікаційних компаніях, застосування відомих математичних методів в телекомунікаціях, дослідження параметрів якості обслуговування в мобільних мережах 5-го покоління. Адреса: Україна, 03058, Київ, пр. Індустріальний, 2, тел. +38-050-607-42-29.

Тимченко Ірина Олегівна, студентка кафедри інформаційно-телекомунікаційних мереж Національного технічного університету "Київський політехничнийінститут ім.І.Сікорського”. Адреса: Україна, 01033, Київ, провул. Індустріальный, 2, моб. тел. +38(096)1267107.

Globa Larisa Sergeevna, professor, doctor of technical sciences, department of Information and Telecommunication networks, National Technical University of Ukraine "Kyiv Polytechnic Institute named after Igor Sikorsky". Scientific interests: intellectual decision support systems, distributed systems and technologies. Address: Ukraine, 01033, Kyiv, pr. Industrualny, 2, mob. +38(050)5261512.

Skulish Maria Anatolievna, PhD, associate professor, Department of Information and Telecommunication networks, National Technical University of Ukraine "Kyiv Polytechnic Institute named after Igor Sikorsky". Scientific interests: security in telecommunication systems, charging systems in telecommunication companies, application of known mathematical methods in telecommunications, research of service quality parameters in mobile networks of the 5th generation. Address: 2, Industrial Avenue, Kyiv, 03058, Ukraine, tel. + 38-050-607-42-29.

Timchenko Iryna Olehivna, student, department of information and telecommunication networks, National Technical University of Ukraine "Kyiv Polytechnic Institute named after Igor Sikorsky". Address: Ukraine, 01033, Kyiv. Industrial, 2, mob. tel. +38 (096) 1267107. 